\title{
Luteal phase of the menstrual cycle increases sweating rate during exercise
}

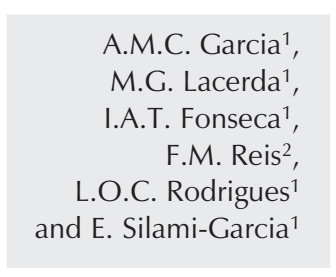

\author{
${ }^{1}$ Laboratório de Fisiologia do Exercício, \\ Escola de Educação Física, Fisioterapia e Terapia Ocupacional, \\ ${ }^{2}$ Departamento de Obstetrícia e Ginecologia, \\ Universidade Federal de Minas Gerais, Belo Horizonte, MG, Brasil
}

\author{
Correspondence \\ E. Silami-Garcia \\ Laboratório de Fisiologia do \\ Exercício \\ Escola de Educação Física, \\ Fisioterapia e Terapia Ocupacional \\ UFMG \\ Av. Antônio Carlos, 6627 \\ 31310-250 Belo Horizonte, MG \\ Brasil \\ Fax: +55-31-3499-2325 \\ E-mail: silami@ufmg.br \\ Research supported by FAPEMIG, \\ CNPq, CAPES, Ministério do Esporte, \\ and Gatorade Sports Science \\ Institute. \\ $\ldots \ldots \ldots \ldots \ldots \ldots$
}

Received September 12, 2005

Accepted June 21, 2006

\begin{abstract}
The present study evaluated whether the luteal phase elevation of body temperature would be offset during exercise by increased sweating, when women are normally hydrated. Eleven women performed 60 min of cycling exercise at $60 \%$ of their maximal work load at $32^{\circ} \mathrm{C}$ and $80 \%$ relative air humidity. Each subject participated in two identical experimental sessions: one during the follicular phase (between days 5 and 8 ) and the other during the luteal phase (between days 22 and 25). Women with serum progesterone $>3 \mathrm{ng} / \mathrm{mL}$, in the luteal phase were classified as group $1(\mathrm{~N}=4)$, whereas the others were classified as group $2(\mathrm{~N}=7)$. Post-exercise urine volume (213 \pm $80 v s 309 \pm 113 \mathrm{~mL})$ and specific urine gravity $(1.008 \pm 0.003$ vs 1.006 $\pm 0.002)$ changed $(\mathrm{P}<0.05)$ during the luteal phase compared to the follicular phase in group 1. No menstrual cycle dependence was observed for these parameters in group 2. Sweat rate was higher $(\mathrm{P}<$ $0.05)$ in the luteal $\left(3.10 \pm 0.81 \mathrm{~g} \mathrm{~m}^{-2} \mathrm{~min}^{-1}\right)$ than in the follicular phase $\left(2.80 \pm 0.64 \mathrm{~g} \mathrm{~m}^{-2} \mathrm{~min}^{-1}\right)$ only in group 1 . During exercise, no differences related to menstrual cycle phases were seen in rectal temperature, heart rate, rate of perceived exertion, mean skin temperature, and pre- and post-exercise body weight. Women exercising in a warm and humid environment with water intake seem to be able to adapt to the luteal phase increase of basal body temperature through reduced urinary volume and increased sweating rate.
\end{abstract}

Key words

- Thermoregulation

- Sweating rate

- Exercise

- Menstrual cycle

- Body temperature

\section{Introduction}

Thermal homeostasis and athletic performance can be influenced by the menstrual cycle. Current evidence suggests that during prolonged exercise in hot conditions there is a decrease in exercise time to exhaustion during the luteal phase of the menstrual cycle, when body temperature is elevated (1). Short- ly after ovulation, when progesterone levels begin to increase, there is a slight and transient temperature elevation that is more evident on awakening in the morning, caused by an upward displacement of the circadian nadir that occurs during this period. The mechanisms of post-ovulation increase of basal body temperature include a resetting of hypothalamic thermostatic centers due to 
neuroendocrine changes triggered by the progesterone surge occurring in the luteal phase (2).

Many studies were conducted in the 1970's and 1980's to investigate possible gender differences in thermoregulation, but they seldom took into account the menstrual cycle and its associated changes of core temperature (3-5). Evidence about the possible effect of the menstrual cycle on thermoregulation during exercise is scarce and contradictory (6-11), although the importance of controlling for the menstrual cycle in thermoregulation studies involving fertile women has been repeatedly emphasized (12-14).

Some studies have suggested that a higher core temperature (rectal or esophageal) can be maintained during exercise performed during the luteal phase, whereas the rate of sweating is unchanged $(7,10)$ or is lower in the luteal than in the follicular phase of the menstrual cycle (11). Heart rate might be either altered $(7,8,10)$ or not $(11)$ depending on the phase of the menstrual cycle. None of these studies, however, controlled fluid balance by measuring urinary parameters and providing water replacement during exercise. Therefore, it is unclear whether exercise-induced dehydration prevented the women in these studies from adequately dissipating heat by reducing total body sweating, thus creating a state of hyperthermia, or whether they were well hydrated and only their temperature set-point remained elevated during exercise.

The aim of the present study was to evaluate the menstrual cycle-related changes in sweating rate and the thermoregulatory adjustments during submaximal exercise in a warm and humid environment. We tested the hypothesis that, under these environmentally stressful conditions, the expected luteal phase elevation of body temperature would be neutralized during exercise by increased sweating if the women are normally hydrated and their water balance is maintained.

\section{Material and Methods}

The study protocol was approved by the Ethics Committee of the Federal University of Minas Gerais. All volunteers received a detailed explanation of the aims and methods of the study and signed an informed consent form prior to participation.

The study was carried out between summer and autumn. To minimize the impact of circadian rhythm on the study variables, testing was always performed between 7:00 and 10:00 am, when the menstrual cycle-related differences in body temperature are more evident (2).

\section{Subjects}

Eleven healthy female college students, 19 to 32 years of age, volunteered for the study. All participants had regular menstrual cycles prospectively assessed for 10 months, and none had used any hormone medication, including oral contraceptives, during the past 12 months. Exclusion criteria were evidence of any reproductive and/or endocrine disorder following a thorough clinical examination.

The subject's body height, weight, percent body fat (15) (Lange ${ }^{\circledR}$ Skinfold Caliper, Santa Cruz, CA, USA), body surface area (16), and $\mathrm{VO}_{2 \max }(17)$ were evaluated before the experiments. A cycle ergometer (Monark ${ }^{\circledR}$ 824E, Varberg, Sweden) was used to evaluate $\mathrm{VO}_{2 \max }$. The initial workload was 50 watts, with 25 -watt increments every 2 min until exhaustion. The equation proposed by the American College of Sports Medicine (17) was used for calculation: $\mathrm{VO}_{2 \max }(\mathrm{mL}$ $\left.\mathrm{O}_{2} \mathrm{~kg}^{-1} \mathrm{~min}^{-1}\right)=300+(12 \mathrm{x}$ maximal workload (watts))/weight (kg).

\section{Study design}

Each subject participated in two identical experimental sessions that took place in random order in the same or in subsequent 
menstrual cycles: one session was performed during the follicular phase (between days 5 and 8 ) and the other during the luteal phase (between days 22 and 25). The cycles were monitored considering the menstrual calendar, basal body temperature charts and serum progesterone measurements. The women who had a serum progesterone concentration compatible with ovulation, i.e., $>3 \mathrm{ng} /$ $\mathrm{mL}$ (18) on the morning of the luteal phase experiment were classified as group 1, whereas those who did not have progesterone levels compatible with ovulation were classified as group 2. The characteristics of the two study groups are summarized in Table 1.

\section{Variables}

Rectal temperature was measured using disposable rectal probes (YSI ${ }^{\circledR} 4400$ series, 4491-E, Yellow Springs, OH, USA) inserted $12 \mathrm{~cm}$ beyond the anal sphincter. Heart rate was measured with a heart rate monitor (Polar Accurex Plus ${ }^{\circledR}$, Kempele, Finland). The rating of perceived exertion was evaluated every 2 min until exhaustion throughout the exercise period (19). Mean skin temperature (Tsk) was determined with thermosensors (YSI ${ }^{\circledR} 400$ series) affixed to the chest, arm, thigh, and leg. The equation proposed by Ramanathan (20) was used for calculation: $\overline{\mathrm{T}} \mathrm{sk}=0.3($ chest + arm $)+0.2($ thigh + leg $)$.

Urine specific gravity $\left(\mathrm{U}_{\mathrm{sg}}\right)$ was measured with a refractometer (JSCP-Uridens ${ }^{\circledR}$, São Paulo, SP, Brazil) (21). Urine volume $\left(\mathrm{V}_{\mathrm{u}}\right)$ was measured using a volumetric flask graduated in $2 \mathrm{~mL}$. $\mathrm{U}_{\mathrm{sg}}$ and $\mathrm{V}_{\mathrm{u}}$ were evaluated prior to and at the end of each experiment.

Total sweat volume was estimated from the pre-to-post body weight change, correcting for both the water intake volume and the volume of urine excreted (22). The sweat rate was calculated by dividing total sweat volume by time between measurements. A digital scale with $0.02-\mathrm{kg}$ precision was used to weigh the participants (Filizola ${ }^{\circledR}$ MF-100 scale, São Paulo, SP, Brazil).

\section{Experimental protocol}

On the day scheduled for each experiment, the volunteers woke up at 6:00 am and drank $500 \mathrm{~mL}$ fresh water (23). They arrived at the laboratory at 7:00 am, rested for 30 min, and had a blood sample collected for progesterone measurement. They received a balanced meal based on the estimated caloric cost of the activity (24).

The subjects exercised in an environmental chamber (Russells ${ }^{\circledR}$ WMD-1150-5s, Holland, MI, USA) set at $32^{\circ} \mathrm{C}$ and $80 \%$ air relative humidity. Volunteers wore sports bras, shorts, socks, and sports shoes throughout the experiments.

The subjects rested for $15 \mathrm{~min}$ by sitting on a chair inside the environmental chamber prior to the beginning of the 60 -min exercise period at $60 \%$ of their individual peak power. Following the exercise period, they remained inside the chamber for an additional 30-min resting period.

The subjects were given volumes of water equivalent to the estimated water loss through sweating $(632.91 \pm 93.99 \mathrm{~mL} / \mathrm{h})$ at every $15 \mathrm{~min}$ of exercise. The method used for estimating sweating has been validated

Table 1. Baseline characteristics of the two groups of volunteers.

\begin{tabular}{lcc}
\hline & Group $1(\mathrm{~N}=4)$ & Group 2 $(\mathrm{N}=7)$ \\
\hline Age (years) & $22.5 \pm 1.7$ & $23.3 \pm 4.2$ \\
Weight $(\mathrm{kg})$ & $57.00 \pm 7.36$ & $56.89 \pm 5.31$ \\
Height $(\mathrm{cm})$ & $164.8 \pm 7.2$ & $166.3 \pm 6.3$ \\
Body surface $\left(\mathrm{m}^{2}\right)$ & $1.62 \pm 0.14$ & $1.63 \pm 0.09$ \\
Body fat $(\%)$ & $20.7 \pm 5.8$ & $20.6 \pm 2.7$ \\
$\mathrm{VO}_{2 \text { max }}\left(\mathrm{mL} \mathrm{kg}^{-1} \mathrm{~min}^{-1}\right)$ & $39.59 \pm 8.83$ & $35.28 \pm 6.25$ \\
Menstrual cycle length (days) & $30.3 \pm 1.2$ & $32.2 \pm 6.9$ \\
Progesterone concentration $(\mathrm{ng} / \mathrm{mL})$ & $8.3 \pm 6.3^{*}$ & $0.7 \pm 0.5$
\end{tabular}

Data are reported as means $\pm \mathrm{SD}$. Group $1=$ serum progesterone concentration compatible with ovulation $(>3 \mathrm{ng} / \mathrm{mL}$ ). Group $2=$ serum progesterone concentration not compatible with ovulation. *Serum progesterone concentration during the luteal phase was significantly higher in group 1 than in group $2(\mathrm{P}<0.05$; unpaired Student $t$ test). 
in our laboratory (Amorim FT, unpublished data) in experiments using different workloads and environmental conditions. To avoid heat exchange with the body, drinking water was supplied at a temperature similar to the subjects' rectal temperature.

\section{Statistical analysis}

The descriptive variables of groups 1 and 2 are reported as means \pm SD and were compared by the unpaired Student $t$-test. Within each group, the results from each of the two experiments (body weight, urinary volume, sweating rate, urinary density) were compared by the paired $t$-test. The variables measured across the experiments were analyzed by two-way analysis of variance (ANOVA) or by multivariate ANOVA using the General Linear Model (SPSS 10.0 Software Package, SPSS Co., Chicago, IL, USA). In all cases, statistical significance was set at $\mathrm{P}<0.05$.

\section{Results}

Heart rate increased substantially during exercise and returned to basal levels within

Table 2. Effects of exercise performed during different phases of the menstrual cycle on body weight and some water balance parameters.

\begin{tabular}{|c|c|c|c|c|}
\hline & \multicolumn{2}{|c|}{ Group $1(N=4)$} & \multicolumn{2}{|c|}{ Group $2(\mathrm{~N}=7)$} \\
\hline & Follicular & Luteal & Follicular & Luteal \\
\hline \multicolumn{5}{|c|}{ Body weight (kg) } \\
\hline Initial & $57.13 \pm 7.18$ & $57.05 \pm 7.11$ & $56.34 \pm 4.81$ & $56.73 \pm 5.12$ \\
\hline Final & $56.86 \pm 7.25$ & $56.82 \pm 7.10$ & $56.16 \pm 4.90$ & $56.42 \pm 5.14$ \\
\hline \multicolumn{5}{|c|}{ Specific urine gravity } \\
\hline Initial & $1.005 \pm 0.003$ & $1.006 \pm 0.002$ & $1.005 \pm 0.002$ & $1.004 \pm 0.002$ \\
\hline Final & $1.006 \pm 0.002$ & $1.008 \pm 0.003^{*}$ & $1.010 \pm 0.006$ & $1.008 \pm 0.004$ \\
\hline \multicolumn{5}{|c|}{ Urinary volume $(\mathrm{mL})$} \\
\hline Initial & $532 \pm 177$ & $587 \pm 352$ & $467 \pm 112$ & $428 \pm 68$ \\
\hline Final & $309 \pm 113$ & $213 \pm 80^{*}$ & $204 \pm 107$ & $240 \pm 120$ \\
\hline
\end{tabular}

Data are reported as means \pm SD. Group $1=$ serum progesterone concentration compatible with ovulation $(>3 \mathrm{ng} / \mathrm{mL}$ ). Group $2=$ serum progesterone concentration not compatible with ovulation. ${ }^{*} \mathrm{P}<0.05$ compared to the follicular phase of the menstrual cycle within the same group (Student $t$-test).
30 min of post-exercise resting. No significant difference related to the phase of the menstrual cycle was observed during exercise $(163.2 \pm 5.7 v s 163.2 \pm 9.7 \mathrm{bpm}$ in the luteal and follicular phases of group 1, respectively; $\mathrm{P}>0.05$ and $166.3 \pm 8.0$ vs 170.4 $\pm 7.6 \mathrm{bpm}$ in the luteal and follicular phases of group 2, respectively; $\mathrm{P}>0.05$ ).

The rate of perceived exertion increased during exercise and no significant differences related to the phase of the menstrual cycle were observed (16 vs 15 in the luteal and follicular phases of group 1, respectively, $\mathrm{P}>0.05$, and $14 v s 13$ in the luteal and follicular phases of group 2, respectively, $\mathrm{P}$ $>0.05)$. Data are reported as median.

Pre- and post-testing body weight did not change according to the phase of the menstrual cycle (Table 2). Water balance parameters such as post-testing specific urine gravity and urinary volume changed significantly during the luteal phase in comparison to the follicular phase in the subjects of group 1 , whereas no menstrual cycle dependence was observed for these parameters among the subjects of group 2 (Table 2). Pre-testing specific urine gravity and urinary volume were not affected by menstrual cycle phase (Table 2).

Mean skin temperature increased during exercise, with no statistically significant differences related to menstrual cycle phases $\left(35.43 \pm 0.47\right.$ vs $35.17 \pm 0.56^{\circ} \mathrm{C}$ in the luteal and follicular phases of group 1, respectively, $\mathrm{P}>0.05$, and $35.20 \pm 0.42$ vs $35.04 \pm$ $0.23^{\circ} \mathrm{C}$ in the luteal and follicular phases of group 2, respectively, $\mathrm{P}>0.05$ ).

Pre-exercise rectal temperature was higher during the luteal phase than during the follicular phase and this difference was restricted to group $1(36.94 \pm 0.03$ vs $36.79 \pm$ $0.03^{\circ} \mathrm{C}$ in the luteal and follicular phases, respectively; $\mathrm{P}<0.05)$. Exercise induced a significant increase of rectal temperature, but the mean temperatures recorded during exercise did not differ between the two groups or according to menstrual cycle (Figure 1). 
Post hoc power calculation showed that the lack of statistically significant differences in rectal temperature during exercise was not due to sample size, which was sufficient to detect a difference of $0.2^{\circ} \mathrm{C}$ with $90 \%$ power and $1 \%$ type one error.

The sweating rate increased during the luteal phase in comparison to the follicular phase, and this menstrual cycle dependence was observed only among subjects of group 1 (median 2.78 vs $3.21 \mathrm{~g} \mathrm{~m}^{-2} \mathrm{~min}^{-1}$ in the follicular and luteal phases, respectively; $\mathrm{P}$ $<0.05$, Figure 2). In group 2, comparison between menstrual cycle phases showed no statistically significant difference (median 2.61 vs $2.59 \mathrm{~g} \mathrm{~m}^{-2} \mathrm{~min}^{-1}$ in the follicular and luteal phases, respectively; $\mathrm{P}>0.05$, paired $t$-test).

\section{Discussion}

We observed that in the group of women who displayed the expected progesterone and basal body temperature increase in the luteal phase, rectal temperature during exercise was maintained at the same levels recorded during the follicular phase. Thus, the reprogramming of basal body temperature seen in the luteal phase was regulated by the adaptation to exercise in a warm and humid environment. It is important to notice that, in our protocol, the women were maintained hydrated by appropriate water intake during exercise. This may have permitted the increase in sweating rate despite the already reduced urinary volume, contrasting with other studies in which the sweating rate was not altered and the core temperature increased $(7,10)$.

Although some controversy persists, sweat regulation during exercise seems to be gender specific $(4,5)$. In women, the effect of the menstrual cycle on sweating rate has been evaluated in the past with inconclusive findings, with the rate being either unchanged $(7,10)$ or lower in the luteal phase $(11)$. In the present study, we observed a third pattern, with an increased sweating rate during the luteal phase. Because all of these studies differ in exercise intensity, environment, fluid intake, and definition of menstrual cycle phase, discrepant results are not surprising.

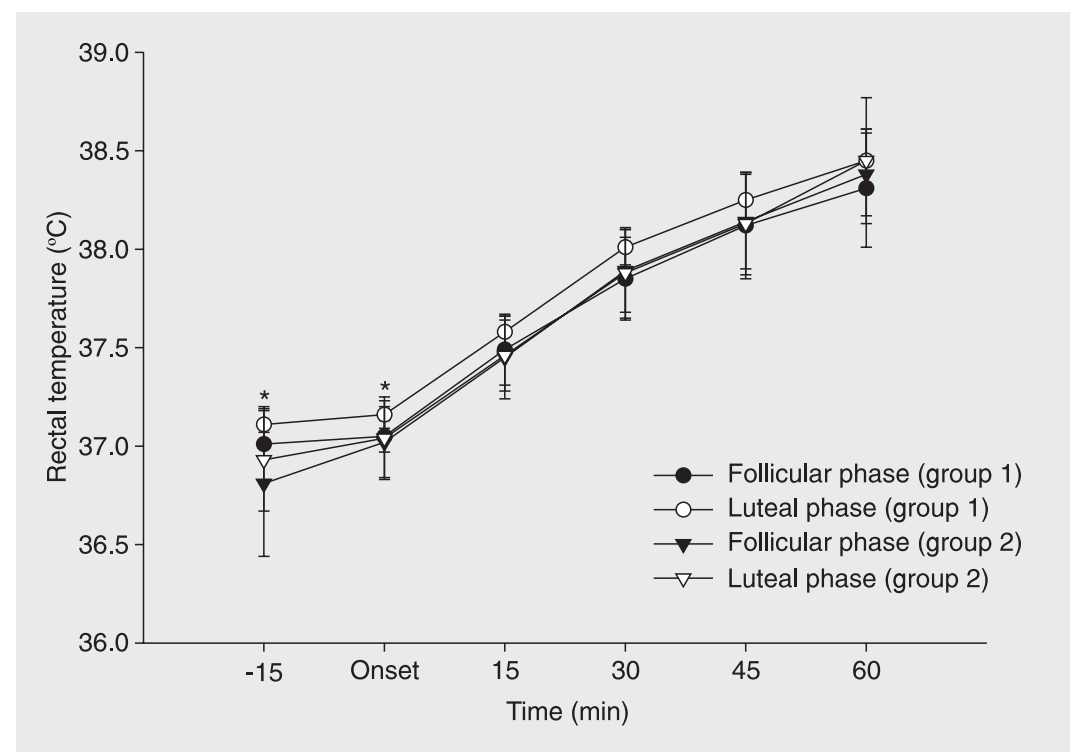

Figure 1. Rectal temperature during the exercise performed in different phases of the menstrual cycle. Group 1 showed serum progesterone and basal temperature elevation in the luteal phase, and group 2 showed no elevations. Data are reported as means \pm SD. Rectal temperature was higher during the luteal phase in comparison to the follicular phase in group $1\left({ }^{*} \mathrm{P}<0.05\right.$, two-way ANOVA).

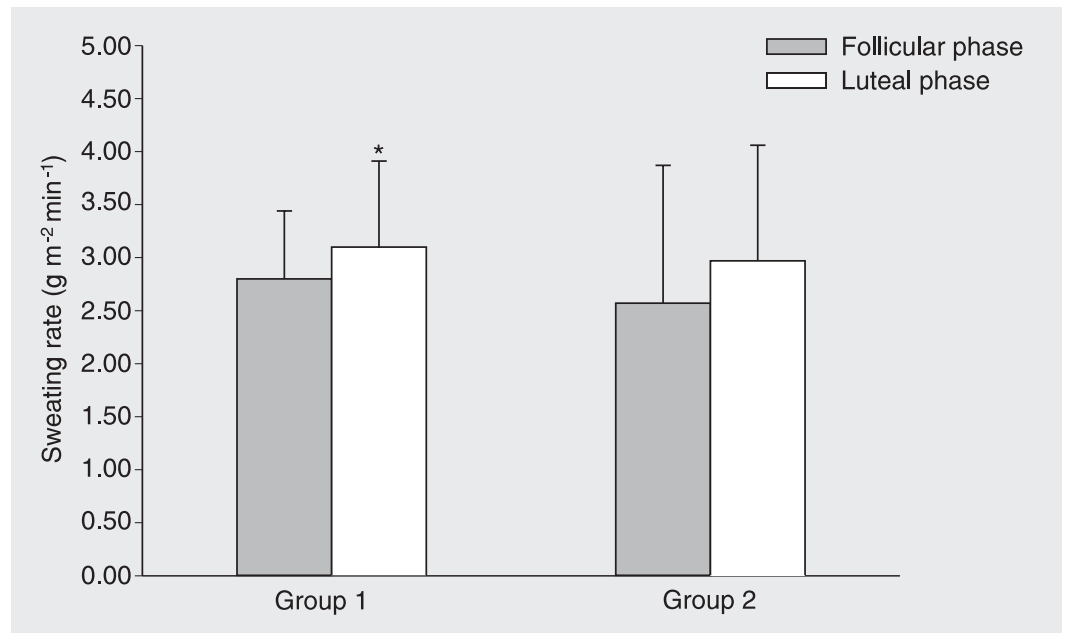

Figure 2. Sweating rate during the exercise performed in different phases of the menstrual cycle. Group 1 showed serum progesterone and basal temperature elevation in the luteal phase, and group 2 showed no elevations. Data are reported as means \pm SD. The sweating rate increased during the luteal phase in comparison to the follicular phase in group $1\left({ }^{\star} \mathrm{P}<\right.$ 0.05 , Student $t$-test). 
Thus, it seems that the menstrual cycle actually can affect sweat control but only in certain exercise situations.

As a consequence of the increased sweating rate, in our experiment the temperature did not increase excessively during the luteal phase compared to the follicular phase, nor did the perceived exertion or heart rate. We (25) and others $(26,27)$ have shown the importance of water replacement during exercise for optimal thermoregulation, with a favorable impact on cardiovascular performance as indicated by heart rate, blood pressure and perceived exertion. Indeed, in the present study there were no differences in heart rate or perceived exertion between the two phases of the menstrual cycle, a fact probably reflecting the optimal thermoregulation achieved during exercise in spite of the increased basal body temperature.

Adequate physiological function is essential for exercising in particular environmental conditions in order to improve the performance and avoid cardiovascular strain $(26,27)$. The present study suggests that women in the luteal phase are able to compensate for the natural elevation of resting temperature by increasing the sweating rate during exercise and thereby preserving optimal thermoregulation and cardiovascular integrity. The results of the present study contrast with studies in which the subjects received no water during exercise $(7,8,10$, 11). Fluid replacement, therefore, might be helpful to equalize thermoregulation in the different menstrual phases during exercise in a warm and humid environment.

We showed that women performing submaximal exercise in a warm and humid environment but with regular water intake seem to be able to adapt to the luteal phase increase of basal body temperature through reduced urinary volume and elevated sweating rate, probably due to an increase in sweating sensitivity.

\section{Acknowledgments}

We would like to thank our volunteers for participating in this study.

\section{References}

1. Janse de Jonge XA. Effects of the menstrual cycle on exercise performance. Sports Med 2003; 33: 833-851.

2. Yen SSC, Jafee RB. Reproductive endocrinology: physiology, pathophysiology and clinical management. 3rd edn. Philadelphia: W.B. Saunders Company; 1991.

3. Wells CL, Horvath SM. Responses to exercise in a hot environment as related to the menstrual cycle. J Appl Physiol 1974; 36: 299-302.

4. Avellini BA, Kamon E, Krajewski JT. Physiological responses of physically fit men and women to acclimation to humid heat. J Appl Physiol 1980; 49: 254-261.

5. Horstman DH, Christensen E. Acclimatization to dry heat: active men vs active women. J Appl Physiol 1982; 52: 825-831.

6. Horvath SM, Drinkwater BL. Thermoregulation and the menstrual cycle. Aviat Space Environ Med 1982; 53: 790-794.

7. Pivarnik JM, Marichal CJ, Spillman T, Morrow JR Jr. Menstrual cycle phase affects temperature regulation during endurance exercise. $J$ Appl Physiol 1992; 72: 543-548.

8. Kolka MA, Stephenson LA. Effect of luteal phase elevation in core temperature on forearm blood flow during exercise. $J$ Appl Physiol 1997; 82: 1079-1083.

9. Stephenson LA, Kolka MA. Esophageal temperature threshold for sweating decreases before ovulation in premenopausal women. $J$ Appl Physiol 1999; 86: 22-28.
10. Fukuoka Y, Kaneko Y, Takita C, Hirakawa M, Kagawa H, Nakamura $Y$. The effects of exercise intensity on thermoregulatory responses to exercise in women. Physiol Behav 2002; 76: 567-574.

11. Kuwahara $T$, Inoue $Y$, Abe $M$, Sato $Y$, Kondo N. Effects of menstrual cycle and physical training on heat loss responses during dynamic exercise at moderate intensity in a temperate environment. $A m \mathrm{~J}$ Physiol Regul Integr Comp Physiol 2005; 288: R1347-R1353.

12. Carpenter AJ, Nunneley SA. Endogenous hormones subtly alter women's response to heat stress. J Appl Physiol 1988; 65: 23132317.

13. Hessemer V, Bruck K. Influence of menstrual cycle on shivering, skin blood flow, and sweating responses measured at night. J Appl Physiol 1985; 59: 1902-1910.

14. Hessemer V, Bruck K. Influence of menstrual cycle on thermoregulatory, metabolic, and heart rate responses to exercise at night. $J$ Appl Physiol 1985; 59: 1911-1917.

15. Jackson AS, Pollock ML, Ward A. Generalized equations for predicting body density of women. Med Sci Sports Exerc 1980; 12: 175181.

16. $\mathrm{Du}$ bois $\mathrm{D}, \mathrm{Du}$ bois EF. A formula to estimate the approximate surface area if height and weight be known. Arch Intern Med 1916; 17: 831-836.

17. American College of Sports Medicine. Manual para teste de esforço 
e prescrição de exercício. 4th edn. Rio de Janeiro: Revinter; 1996.

18. Israel R, Mishell DR Jr, Stone SC, Thorneycroft IH, Moyer DL. Single luteal phase serum progesterone assay as an indicator of ovulation. Am J Obstet Gynecol 1972; 112: 1043-1046.

19. Borg GA. Psychophysical bases of perceived exertion. Med Sci Sports Exerc 1982; 14: 377-381.

20. Ramanathan NL. A new weighting system for mean surface temperature of the human body. J Appl Physiol 1964; 19: 531-533.

21. Armstrong LE. Heat and humidity. In: Armstrong LE (Editor), Performing in extreme environments. Champaign: Human Kinetics; 2000. p 15-70.

22. National Athletic Trainers' Association - Position Statement. Fluid replacement for athletes. J Athl Train 20000; 35: 212-224.

23. American College of Sports Medicine - Position Stand. Exercise and fluid replacement. Med Sci Sports Exerc 1996; 28: 1-7.
24. Ainsworth BE, Haskell WL, Whitt MC, Irwin ML, Swartz AM, Strath SJ, et al. Compendium of physical activities: an update of activity codes and MET intensities. Med Sci Sports Exerc 2000; 32: S498S504.

25. Guimaraes MT, Silami-Garcia E. Water replacement and thermoregulatory responses during prolonged exercise. Braz J Med Biol Res 1993; 26: 1237-1240.

26. Sawka MN. Physiological consequences of hypohydration: exercise performance and thermoregulation. Med Sci Sports Exerc 1992; 24: 657-670.

27. Armstrong LE, Maresh CM, Gabaree CV, Hoffman JR, Kavouras SA, Kenefick RW, et al. Thermal and circulatory responses during exercise: effects of hypohydration, dehydration, and water intake. $J$ Appl Physiol 1997; 82: 2028-2035. 